\title{
USING REMOTE-SENSING TO IDENTIFY WINTERING AND MOULTING AREAS OF A LONG-DISTANCE MIGRANT: MARSH WARBLER (ACROCEPHALUS PALUSTRIS)
}

\author{
MiHOLCSA, T. $.^{*}-$ HARNOS, A. ${ }^{2}-$ CSÖRGÖ, T. ${ }^{1}$ \\ ${ }^{1}$ Eötvös Loránd University, Department of Anatomy, Cell- and Developmental Biology \\ Pázmány Péter sétány 1/C, 1117 Budapest, Hungary \\ ${ }^{2}$ Szent István University, Faculty of Veterinary Science, Department of Biomathematics and \\ Informatics, István u. 2, 1078 Budapest, Hungary \\ *Corresponding author: \\ e-mail:mihhok@gmail.com \\ (phone: +40-722-457464; fax: +40-372-251176) \\ (Received $2^{\text {nd }}$ Mar 2015; accepted $27^{\text {th }}$ Jan 2016)
}

\begin{abstract}
Ecological conditions in wintering quarters strongly influence the survival of long-distance migrant species, moreover food abundance and quality in moulting areas determine feather growth rate and wing length too. These circumstances via net primary production can be well characterized by the Normalized Difference Vegetation Indices (NDVI) of the respective areas. In this paper we approach this subject from the opposite direction: supposing this strong relationship between vegetation indices and survival, respectively moult, we try to identify putative wintering and moulting areas of Marsh Warblers (Acrocephalus palustris) with the help of Spearman`s rank correlations between annual survival indices, wing lengths and NDVI from entire Africa. We have chosen this species because its movements, stopover sites and wintering areas are relatively well known compared to other trans-Saharan migrants, hence with the help of the literature we can test the validity of our results. In lack of sufficient ringing-recapture data we have applied a new survival index which is based on the ratio of the abundances of different age classes. Our results are consistent with the available information from literature showing that our survival index, wing lengths and our methods are appropriate to search for putative wintering and/or moulting areas.
\end{abstract}

Keywords: migratory bird, moult, survival, wintering, NDVI

\section{Introduction}

In the Palearctic-African migration system the ecology of migratory birds is much better understood on their breeding grounds. Pertinent knowledge to their migration routes and wintering quarters is scarce, in case of many species it is alarmingly little known about these areas. Although wintering quarters of species is more or less known due to presence-absence data from various regions of the African continent, the geographic distribution of different populations within these areas is still mainly unknown.

In the last decades the populations of long-distance Afro-Palearctic migrants have shown an alarming declining trend (Vickery et al., 2014). Because of the strong connectivity and carry over effects across continents, ecological conditions on wintering quarters influence population trends of many long-distance migrants on their breeding grounds (Ockendon et al., 2014). Therefore it is essential to study the complete lifecycle of these birds, and we need more precise information about the wintering quarters of distinct populations. 
Despite the strong ringing efforts in Europe there are few recoveries in Africa, so by the traditional ringing-recapture method there is very little information accumulated about wintering areas of different species. For example from all (35197 specimens) of the Marsh Warblers ringed in Hungary only one was recaptured in Africa (Kenya) (Csörgö \& Gyurácz, 2009). Hence new methods are needed to efficiently identify and study wintering areas of long-distance migrants (Szép et al., 2006). Although GPS tags are becoming more and more widespread, there still is a size limit. On small birds (e.g. passerines) only geolocators can be mounted, but they have to be recaptured to download data (Emmenegger et al., 2014). In long-distance migrants this is possible only among species with strong site-fidelity which is not the case of Marsh Warblers. The return rates to previous years breeding area are 10-57\% of the Marsh Warblers, but the rate to natal areas is lower (Dowsett-Lemaire, 1978). Although the breeding site fidelity is high, because of the fixed locations of the standardized net-standings the probability of recapture is low if the birds do not return exactly (within a few meters) to their previous year breeding-site. Because it is a territorial species, the number of territories (breeding birds) are low along the net-lines. Therefore new methods still need to be developed which are cheap and can cover large areas and analyze a large amount of data. Because of the strong correlations with survival a very promising candidate is the NDVI.

The rapid technical development of computers in the recent past made possible the widespread use of analytical methods based on remote sensing. In ecology the most expansively used dataset is the NDVI - Normalized Difference Vegetation Index (Pettorelli et al., 2005).

NDVI is basically an expression of primary production, which especially in arid and semi-arid habitats strongly correlates with rainfall. NDVI is generally used in bird studies, as a describer of the ecological conditions: through net primary production (NPP) it expresses food abundance (Phillips et al., 2008) for herbivorous, but also for insectivorous birds.

Gordo (2007) offers a review of weather and climate effects on avian migratory phenology and highlights the importance of remote sensing in the research of migration and wintering. In stop-over sites and wintering areas net primary production (NPP) determines food availability for herbivorous but also for insectivorous birds (eg. Marsh Warblers) and is strongly correlated with NDVI (Trierweiler et al., 2013).

In several studies it has been shown, that the climatic and ecological conditions (NPP) in the wintering quarters and en-route have a great impact on body condition (Studds \& Marra, 2007; Balbontín et al., 2012) and therefore on wintering bird survival (Schaub et al., 2005; Eraud et al., 2009; Grande et al., 2009; Mihoub et al., 2010).

In this paper with the help of NDVI we will try to identify the wintering quarters of Marsh Warblers using a simple survival index, and to refine the moulting areas through annual average wing lengths. Because it is a novel method with just a few similar attempts (Szép et al., 2006; Ambrosini et al., 2011), we have chosen a trans-Saharan migrant whose wintering and moulting quarters are well known in comparison with other species.

Our main objective is to test the suitability of a simple survival index calculated from autumn migration ringing data for searching/studying wintering areas using remote sensing datasets. We have not used spring migration data, because the Marsh Warbler is a late migrating species, arriving to its breeding grounds in late April, early May, when 
the breeding of other species has already begun. To avoid the disturbance of breeding, we don`t trap intensively birds in this period, hence our spring data are scarce.

Marsh Warbler is a species which moults during winter (Svensson, 1992), therefore based on the NDVI-feather length relationship (Saino et al., 2004), annual variation in wing-length compared to annual variation of NDVI could give us useful information about moulting/wintering grounds. Therefore similarly to the survival index we would like to search those putative quarters, where the studied Marsh Warblers (birds breeding in- or migrating through Hungary) moult. This species has intra-continental movements at wintertime (Dowsett-Lemaire \& Dowsett, 1987), therefore the areas where birds are present before-, during- and after moult, do not necessarily overlap. Hence it would be interesting to compare the resulted areas from the investigations of the survival indexNDVI, respectively wing-length NDVI relationships.

The leading idea of these calculations is that if survival in the wintering period has a major role in annual survival, than the fluctuation of annual survival indices will follow the year-to year fluctuation of NPP (NDVI values) on wintering quarters in the period when the studied species is present. The same should be true for wing length and food abundance in moulting areas expressed by NDVI.

\section{Methods}

\section{Bird data}

The standardized trapping at Ócsa Ringing Station (Duna-Ipoly National Park - Ócsa Landscape Protected Area (N47. 294805; E19.206266)) begins each year on the 10th of July and lasts until the end of October covering the whole migration of these species. The age class (adult, juvenile) of every individual was determined and the wing length was measured with $1 \mathrm{~mm}$ accuracy. Since Marsh Warblers are early migrants (adults depart in second half of July, middle of August (Cramp \& Brooks, 1992; Csörgö \& Gyurácz, 2009). The majority of ringed birds are migrants, originated from the northwestern part of the breeding area of the species (Norway, Sweden, Denmark, Belgium, Germany, Austria, Czech Republic (Csörgő \& Gyurácz, 2009; BirdLife International, 2015) but we cannot separate them from the local breeders being in postjuvenile/postnuptial dispersion.

In our studies we have calculated survival indices ( $\mathrm{Si}$ ) from 1222 adult (annual mean \pm SD: 49.42 \pm 26.07 ) and 3078 juvenile (annual mean: 125.21 \pm 77.74 ) Marsh Warblers ringed between 1984-2008:

$$
\mathrm{Si}=\frac{\mathrm{N}_{\mathrm{ad}(\mathbb{T})}}{\mathrm{N}_{\mathrm{ad}(\mathbb{T}-1)}+\mathrm{N}_{\mathrm{juv}(\mathrm{T}-1)}}
$$

where: $\mathrm{Si}$ - survival index; $\mathrm{N}_{\mathrm{ad}(\mathrm{T})}$ - total number of adult birds in a year; $\mathrm{N}_{\mathrm{ad}(\mathrm{T}-1)}-$ total number of adults in the year before; $\mathrm{N}_{\mathrm{juv}(\mathrm{T}-1)}$ - total number of juveniles in the year before.

The idea behind this survival index is that adults in a given year are the survivors from the total number of birds (adults and juveniles) from previous year. The ratio of these two numbers is an approximation of annual survival of the studied populations (mean over the studied years: $0.398 \pm 0.361$ ). Therefore with this index based on ageclass ratios we attempt to describe the annual survival of the migrating population, 
which - due to the strong genetic control of migration routes of long-distance migrants (Berthold, 1995) - is the same every year.

In wing length calculations only adult birds were included because their wing feathers were moulted/grown in Africa. Wing lengths of 1170 adult birds ringed between 1984-2008 were analyzed (annual mean number of adults 48.75 \pm 24.24 ), average of annual wing length means: $68.31 \pm 0.5 \mathrm{~mm}$ (StatSoft, 2007). Because the number of adult caught by standardized conditions was critically low in 1987, we have not included this year in the calculations.

Ringed birds (recaptures) have been excluded from both analyses.

We checked if there is any long-term change in wing length with linear mixed model against years and, with ordinary linear regression in case of survival indexes.

These calculation were than using the R 3.02 program and the "nlme" package (R Core Team, 2013; Pinheiro et al., 2014).

\section{NDVI data}

We have downloaded NOAA AVHRR NDVI datasets (datasets created by the Advanced Very High Resolution Radiometer sensors of National Oceanic and Atmosphere Administration (USA) satellites) from the NOAA website. These images have a resolution of $8 \times 8 \mathrm{~km}$, every image containing $1152 \times 1152$ pixels, covering the entire African continent.

We have calculated average vegetation indices for the period from 1. January-31. March each year. This interval represents the main wintering period of Marsh Warblers in final wintering areas (Cramp \& Brooks, 1992).

From the annual decadal NDVI values of the studied 24 years (1985-2008) we have calculated the average NDVI for every 10 day interval from 1. January until 31. March. Then we have calculated the slopes for each pixel for the succession of these 10 day averages for the studied interval (January-March). The slope value (trend) of each pixel was visualized on a map by a color scale. The goal of these investigations was to determine if there is any trend and/or geographical pattern in vegetation greenness (weather, rainfall) in the studied three months.

We have analyzed bird data only until 2008 because the NOAA AVH RR NDVI datasets are not available from 2009.

\section{Calculations}

From the time series of survival indices and wing lengths Spearman's rank correlations have been calculated with time series of NDVI data for each pixel of Africa.

We have illustrated on the map of Africa those pixels where the resulted Spearman`s $\mathrm{R}$ values were positive and greater than 0.5. Calculations have been done with STATISTICA 8.0 software (StatSoft, 2007).

Hereby every map is a result of more than 1.3 million (1152x1152) Spearman rank correlations over a time series of 24 years. 


\section{Results}

On the maps of correlations between survival indices and mean January-March NDVI a major southern African patch is formed by the southern and eastern parts of Namibia, Botswana and the western region of South Africa (Fig. 1). A small patch also appeared near the eastern shores of South Africa, in the Natal region. According to our theory and methods these are the main wintering quarters of those Mash Warbler populations which migrate through the Carpathian Basin.

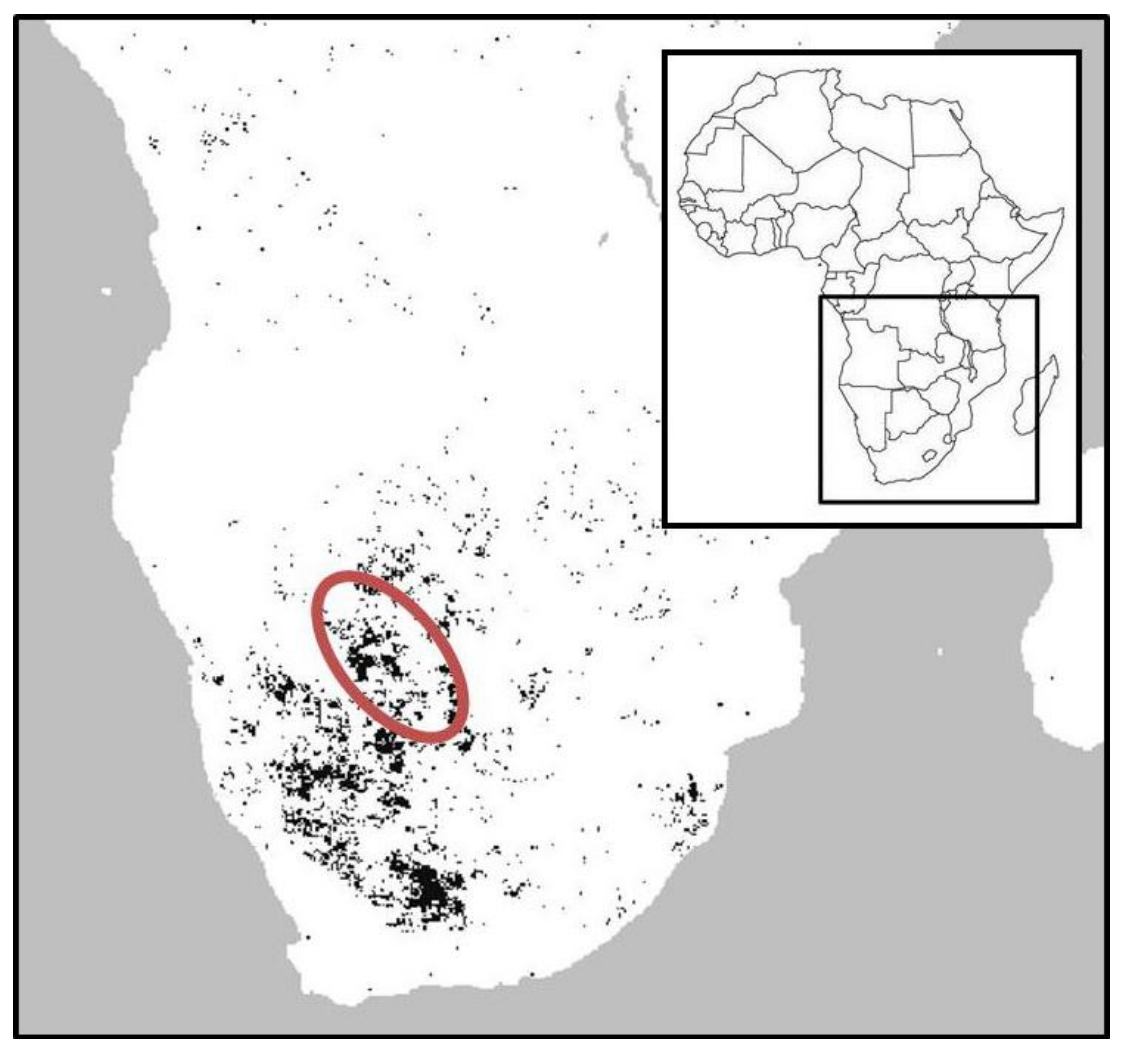

Figure 1. Pixels $(8 \times 8 \mathrm{~km})$ with positive correlations with $R$ value greater than 0.5 between survival indices and NDVI (1985-2008), highlighted zone: the overlap between the two resulted maps

When we have correlated average wing lengths with the NDVI values for the same period, on the resulted map the main regions with positive correlations were: a small, north-eastern part of Namibia, Botswana, southern Zimbabwe and the eastern part of the Republic of South-Africa (Fig. 2). According to our method these are the hypothetical moulting areas of the north-western European Marsh Warblers sampled at Ócsa, Hungary. The above mentioned resulted moulting and wintering regions partially overlap in Botswana (this area is highlighted in Fig. 1-2).

In the studied period of year (January-February-March) the decadal NDVI averages did not show any trend or geographical pattern between the latitudes of the resulted moulting region. In the southern half of the resulted wintering quarters between 1 . January - 31. March NDVI values seem to increase in the eastern regions whereas they decrease in western parts of the Republic of South Africa. 


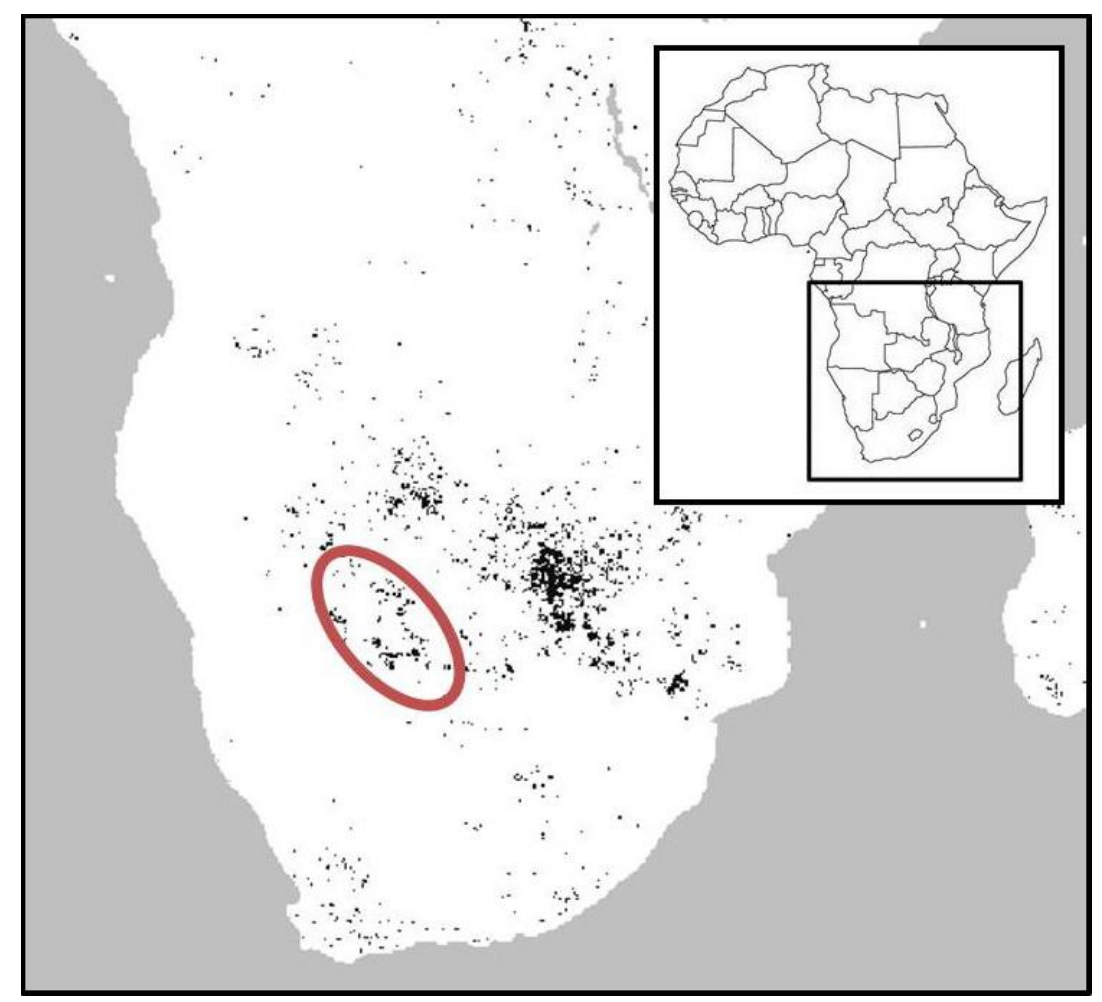

Figure 2. Pixels $(8 \times 8 \mathrm{~km})$ with positive correlations with $R$ value greater than 0.5 between wing lengths and NDVI (1985-2008), highlighted zone: the overlap between the two resulted maps

\section{Discussion}

The Marsh Warbler is a species with western Palearctic distribution (breeding area from western Europe to western Asia) (Cramp \& Brooks, 1992). It is a typical bottleneck migrant species. The birds from the whole breeding area migrate through a thin bottleneck near the Middle East and East Africa. Thus migrants from the western side of the distribution area are heading to south-east and they are passing through the Carpathian Basin. Therefore recaptures with Hungarian concern have originated from Belgium, Germany and Czech Republic (Csörgö \& Gyurácz, 2009). One bird was recaptured in Hungary from Israel and another from Kenya (Csörgő \& Gyurácz, 2009). Recovery data on the migration route including Hungary are from breeding areas including: Denmark, Germany, Austria (Honza et al., 2000), Belgium, Denmark, Germany, Austria, Czech Republic, Hungary (Cepák et al., 2008), Sweden, Denmark, Netherland, Belgium, Germany, Switzerland, Italy, Slovenia, Austria, Czech Republic and Poland (Bairlein et al., 2014). Migration/wintering areas of these populations include: Cyprus, Kenya, Malawi (Honza et al., 2000), Germany, Austria, Czech Republic, Hungary, Cyprus, Kenya, Malawi and The Republic of South Africa (Cepák et al., 2008), Cyprus, Turkey, Syria, Israel, Egypt and Kenya (Bairlein et al., 2014).

This species migrates through the Middle East where the direction of passage changes from south-east to south and birds turn towards the Red Sea coast and the eastern part of Sahel. In this region they can spend up to three months in a supposed autumn quarter (Dowsett-Lemaire \& Dowsett, 1987; Jones, 1995; Yohannes et al., 2005). 
In December Marsh Warblers continue their southward migration in the eastern part of Africa towards Tanzania, Zambia, Malawi, Mozambique and South Africa. Last arrivals are crossing Kenya and Zambia in January. Return migration starts in March (DowsettLemaire \& Dowsett, 1987). This means that most of Marsh Warblers spend January, February and March in southern Africa. Although most recoveries are from the coastal regions of South Africa, Marsh Warblers were caught also in Namibia (Becker \& Lütgens, 1976), so their presence is proven in our "artificial" wintering areas. The number of recapture depend on organized ringing activity, therefore the locations of recaptures mainly reflect the positions of ringing stations, which are not evenly distributed over Africa. Hence recaptures do not reflect precisely the distribution of birds, rather data supply. There might be strong differences in the intensity of field birdwatching in different regions of the Republic of South Africa, therefore our knowledge about wintering quarters might be distorted. According to the Southern African Bird Atlas Project (SABAP) 2 (http://sabap2.adu.org.za/coverage.php \#menu_top) in those parts of the calculated wintering areas which fall outside the wintering quarters known from the literature the intensity of field birdwatching is very low/inexistent. Hence there is a high probability that our results are correct and Marsh Warblers winter there, just up to this point they have not been noticed. There might be strong differences in the intensity of field birdwatching in different regions of the Republic of South Africa, therefore our knowledge about wintering quarters might be distorted. According to the Southern African Bird Atlas Project (SABAP) 2 (http://sabap2.adu.org.za/coverage.php\#menu_top) in those parts of the calculated wintering areas which fall outside the wintering quarters known from the literature the intensity of field birdwatching is very low/inexistent. Hence there is a high probability that our results are correct and Marsh Warblers winter there, just up to this point they have not been noticed. Therefore there is a need for methods which are independent from ringing stations and/or field ornithologists. For this purpose remote-sensing is ideal, but it is essential to validate results with field observations.

Becker and Lütgens (1976) mist netted Marsh Warblers in arid Namibia in dense thornveld dominated by Acacia karroo. This also underpins the plausibility of our results, namely that Marsh Warblers can overwinter in arid habitats far away from coastal regions.

Although some Marsh Warblers start the moult in "hypothetical autumn quarters" somewhere in Ethiopia or nearby places in September-November ), this is only a partial (body) moult (Yohannes et al., 2005; Kennerly \& Pearson, 2010; Leisler \& SchulzeHagen, 2011). Pearson (1982) mentions that from the huge numbers of migrating Marsh Warblers in Kenya only few birds have suspended moult in early January, the majority of the birds having worn primariy feathers in November - December. This information is supported by the fact, that Yohannes (2005) in Kenya has collected only freshly moulted tertials from Marsh Warblers. Although some of the birds can overwinter and moult in Kenya in February and March (Dowsett-Lemaire \& Dowsett, 1987), generally moulting starts in south Zambia and Malawi, and en masse moulting of birds begins only in second half of January in Zimbabwe (Dowsett-Lemaire \& Dowsett, 1987; Kelsey, 1989).

Information in literature are scarce and slightly contradictious: Marsh Warblers finish their moult in southern Zambia and Malawi by the end of March (DowsettLemaire \& Dowsett, 1987; Kelsey, 1989), but first individuals can arrive in the coastal region of South-Africa as soon as late-November, and from the end of December they 
become numerous in this region (Dowsett-Lemaire \& Dowsett, 1987). Becker and Lütgens (1976) mentions that Marsh Warblers can also moult in coastal South-Africa (Natal and Transvaal) in January-February, and/or in Namibia (March). We have found small areas of positive correlations in coastal South African regions too: near Port Elizabeth and to north and east from Cape Town, once again demonstrating the validity of our results. Although a partial moult can begin in Ethiopia, this species moults primaries (the feathers determining wing length) in their primal wintering quarters which can cover a large area formed by Kenya, Zambia, Malawi, the coastal zones of South Africa or Namibia. The percentage and origin of birds moulting in various places is still unknown.

Our resulted moulting quarters in north-eastern Namibia, Botswana, southern Zimbabwe, and some coastal (near Port Elizabeth and to north and east from Cape Town) and eastern South African regions totally suit current knowledge. We have found low number of pixels with positive $\mathrm{R}$ values above 0.4 in the area of "hypothetical autumn quarters" mentioned by Dowsett-Lemaire (1987), Jones (1995) and Yohannes (2005), but they were scarce with scattered distributions, hence we didn 't took them into account. The Natal region mentioned by Becker and Lütgens (1976) is visible only on the maps resulted from the correlations with survival indices.

Comparing our results for moulting and/or wintering areas we can conclude that the studied Marsh-Warblers moult in the above mentioned regions and after completing the moult they continue their intra-continental migration towards south - south-west to final wintering quarters in South Africa and Namibia. These movements can be interpreted also as a post-moult dispersion. These two regions (Fig. 1-2) partially overlap in Botswana, suggesting that for some birds beyond the moulting area this region is the final wintering quarter too.

Summing up the information from literature with our results it seems that the Marsh Warbler population which we sample at Ócsa, Hungary (originated from north-western Europe) moults in parts of Namibia, Botswana, Zimbabwe and Mozambique probably in January-February and they continue their further south to the areas. Some of the birds may overwinter in the overlapping region in Botswana without continuing their southward migration and another fraction of birds moult their wings in the coastal regions of South Africa. Based on our results we can pronounce that the moulting and overwintering birds in Kenya mentioned by Dowsett-Lemaire (1987) do not originate from the north-western part of the species area. None of our results contradict current knowledge about the moult and wintering of Marsh Warblers.

In March Marsh Warblers begin their northward migration from the wintering quarters, latest individuals depart in late April (Cramp \& Brooks, 1992).

We are aware that our survival indices are not so precise as survival rates calculated from ringing-recovery data, but they are based on a large number of birds sampled with standardized methods in standardized periods, therefore they can be treated as indices for the whole migrating population which has been sampled. Although the annual survival of birds in different parts of Europe can be influenced by local factors (bad weather etc.), it is unlikely that these local events will distort remarkably the survival index calculated for a migrating population originating from a large area on continental level (in our case North-Western Europe). Considering these factors we conclude that this method is usable only on species where survival in the wintering period strongly influences the total annual survival, which seems to be true for Marsh Warblers. 
We are conscious about the fact that birds migrating through the Carpathian Basin stem from a large geographical area and wing lengths can vary in function of migration distance (Fiedler, 2005; Förschler \& Bairlein, 2011).

Similarly to survival indices, we consider that average wing lengths are comparable between years because every year we sample Marsh Warblers originating from the same areas. Therefore in our analyses we are studying annual variations of the same northwestern European Marsh Warbler population instead of comparing different populations. Wintering survival and wing length variations should be independent from the geographical origin of birds in Europe because they all follow the same migration route in Africa, which is under strong genetic control (Berthold, 1995).

It is important to be aware that this method draws on the map regions whose climatic fluctuations over time are similar to the fluctuations of bird survival and wing length. In this manner beyond the areas, where birds are present, as a byproduct, can also appear regions with similar (or opposite) weather trends, where birds are clearly absent. False results in deserts are negligible, because NDVI values of bare soil or sand are near zero, and Spearman`s rank correlations considers the rank instead of the value. Thus from near-zero values apparently strong correlations can occur poorly by chance without any biological meaning. The same can be true also for rain-forests, where the NDVI is saturated.

This does not mean that the method is unsuitable, only that the results have to be treated as narrowed putative areas which contain also the real regions (stop-over sites, wintering quarters) that influence bird survival or any other studied variable.

As final conclusion we consider that this method has proved to be usable for investigations on wintering quarters of different species. It is also suitable to spot patterns and to identify putative wintering areas of different populations in the African distribution of the given species.

In this wise we can predict regions that can be crucial in the life-cycle of longdistance migrants but it is essential to visit these areas and to control these findings in field studies too.

Acknowledgements. The authors express their gratitude for the work of the volunteers at the Ócsa Bird Ringing Station from the beginning to this day. This work was supported by OTKA under Grant No. 108571 and by the Research Faculty Grant 2014 of the Szent István University, Faculty of Veterinary Science. We would also like to thankJános Török for his advisements related to the manuscript and Győző Felvinczi for his help in statistical programming.

\section{REFERENCES}

[1] Ambrosini, R., Orioli, V., Massimino, D., Bani, L. (2011): Identification of Putative Wintering Areas and Ecological Determinants of Population Dynamics of Common House-Martin (Delichon urbicum) and Common Swift (Apus apus) Breeding in Northern Italy. - Avian Conservation and Ecology 6: 3.

[2] Bairlein, F., Dierschke, J., Dierschke, V., Salewski, V., Geiter, O., Hüppop, K., Köppen, U., Fiedler, W. (2014): Atlas des Vogelzugs - Ringfunde deutscher Brut- und Gastvögel. - AULA-Verlag, Wiebelsheim.

[3] Balbontín, J., Møller, A. P., Hermosell, I. G., Marzal, A., Reviriego, M., Lope, F. D. (2012): Lifetime individual plasticity in body condition of a migratory bird. - Biological Journal of the Linnean Society 105: 420-434. 
[4] Becker, P., Lütgens, H. (1976): Sumpfrohrsänger (Acrocephalus palustris) in Südwestafrikas. - Madoqua 9: 41-44.

[5] Berthold, P. (1995): Control of Bird Migration. - Chapman \& Hall, London.

[6] BirdLife International (2015): Species factsheet: Acrocephalus palustris. - Downloaded from http://www.birdlife.org on 08/01/2015.

[7] Cepák, J., Klvaňa, P., Formánek, J., Horák, D., Jelínek, M., Schröpfer, L., Škopek, J., Zárybnický, J. (2008): Atlas migrace ptáků České republiky a Slovenska. - Aventinum, Praha.

[8] Cramp, S., Brooks, D. J. (1992): The Birds of the Western Palearctic. - Oxford University Press.

[9] Csörgő, T., Gyurácz, J. (2009): Marsh Warbler. - In: Csörgő T., Karcza Zs., Halmos G., Magyar G., Gyurácz J., Szép T., Bankovics A., Schmidt A., Schmidt E. Hungarian Bird Migration Atlas. Kossuth Kiadó, Budapest.

[10] Dowsett-Lemaire, F., Dowsett, R. J. (1987): European Reed and Marsh Warblers in Africa: migraion patterns, moult and habitat. - Ostrich 58: 65-85.

[11] Dowsett-Lemaire, F. (1978). Annual turnover in a Belgian population of Marsh Warbler, Arocephalus palustris. - Gerfaut 68: 519-532

[12] Emmenegger, T., Hahn, S., Bauer, S. (2014): Individual migration timing of common nightingales is tuned with vegetation and prey phenology at breeding sites. - BMC Ecology 14: doi:10.1186/1472-6785-1114-1189.

[13] Eraud, C., Boutin, J-M., Riviere, M., Brun, J., Barbraud, C., Lormee, H. (2009): Survival of Turtle Doves Streptopelia turtur in relation to western Africa environmental conditions. - Ibis 151: 1869-1190.

[14] Fiedler, W. (2005): Ecomorphology of the External Flight Apparatus of Blackcaps (Sylvia atricapilla) with Different Migration Behavior. - Annals New York Academy of Sciences 1046: 253-263.

[15] Förschler, M. I., Bairlein, F. (2011): Morphological Shifts of the External Flight Apparatus across the Range of a Passerine (Northern Wheatear) with Diverging Migratory Behaviour. - PloS ONE 6: e18732.

[16] Gordo, O. (2007): Why are bird migration dates shifting? A review of weather and climate effects on avian migratory phenology. - Climate Research 35: 37-58.

[17] Grande, J. M., Serrano, D., Tavecchia, G., Carrete, M., Ceballos, O., Díaz-Delgado, R., Tella, J. L., Donázar, J. A. (2009): Survival in a long-lived territorial migrant: effects of life-history traits and ecological conditions in wintering and breeding areas. - Oikos 118: 580-590.

[18] Honza, M., Literák, I., Pavelka, J., Formánek, J. (2000): Postbreeding Occurence of the Marsh Warbler Acrocephalus palustris in Reedbed Areas in the Czech Republic and its Migration to Africa. - Ökologie der Vögel 22: 119-129.

[19] Jones, P. J. (1995): Migration strategies of palearctic passerines in Africa. - Israel Journal of Zoology 41: 393-406.

[20] Kelsey, M. G. (1989): A comparison of the song and territorial behaviour of a longdistance migrant, Marsh Warbler Acrocephalus palustris, in summer and winter. - Ibis 130: 403-414.

[21] Kennerly, P., Pearson, D. (2010): Reed and bush warblers. - London, Christofer Helm Publishers Ltd, London.

[22] Leisler, B., Schulze-Hagen, K. (2011): The Reed Warblers - Diversity in a uniform bird family. - KNNV Publishing.

[23] Mihoub, J.-B., Gimenez, O., Pilard, P., Sarrazin, F. (2010): Challenging conservation of migratory species: Sahelian rainfalls drive first-year survival of the vulnerable Lesser Kestrel Falco naumanni. - Biological Conservation 143: 839-847.

[24] Ockendon, N., Johnston, A., Baillie, S. R. (2014): Rainfall on wintering grounds affects population change in many species of Afro-Palaearctic migrants. - Journal of Ornithology 155: 905-917. 
[25] Pearson, D. J. (1982): The migration and wintering of Palearctic Acrocephalus warblers in Kenya and Uganda. - Scopus 6: 49-59.

[26] Pettorelli, N., Vik, J. O., Mysterud, A., Gaillard, J.-M., Tucker, C. J., Stenseth, N. C. (2005): Using the satellite-derived NDVI to assess ecological responses to environmental change. - TRENDS in Ecology and Evolution 20: 15-27.

[27] Phillips, L. B., Hansen, A. J., Flather, C. H. (2008): Evaluating the species energy relationship with the newest measures of ecosystem energy: NDVI versus MODIS primary production. - Remote Sensing of Environment 112: 4381-4392.

[28] Pinheiro J., Bates D., DebRoy S., Sarkar D., R Core Team (2014):_nlme: Linear and Nonlinear Mixed Effects Models_. R package version 3.1-117, <URL: http://CRAN.Rproject.org/package $=$ nlme $>$.

[29] R Core Team (2013): R: A language and environment for statistical computing. R Foundation for Statistical Computing, Vienna, Austria. URL http://www.R-project.org/.

[30] Saino, N., Szép, T., Ambrosini, R., Romano, M., Møller, A. P. (2004): Ecological conditions during winter affect sexual selection and breeding in a migratory bird. Proceedings of the Royal Society B: Biological Sciences 271: 681-686.

[31] Schaub, M., Kania, W., Köppen, U. (2005): Variation of primary production during winter induces synchrony in survival rates in migratory white storks Ciconia ciconia. Journal of Animal Ecology 74: 656-666.

[32] Statsoft (2007): STATISTICA 8.0. - www.statsoft.com

[33] Studds, C. E., Marra, P. P. (2007): Linking fluctuations in rainfall to nonbreeding season performance in a long-distance migratory bird, Setophaga ruticilla. - Climate Research 35: 115-122.

[34] Svensson, L. (1992): Identification Guide to European Passerines. - Heraclio Fournier SA, Vitoria.

[35] Szép, T., Møller, A. P., Piper, S., Nuttall, R., Szabó, Z. D., Pap, P. L. (2006): Searching for potential wintering and migration areas of a Danish Barn Swallow population in South Africa by correlating NDVI with survival estimates. - Journal of Ornithology 147: 245-253.

[36] Trierweiler, C., Mullié, W. C., Drent, R. H., Exo, K.-M., Komdeur, J., Bairlein, F., Harouna, A., Bakker, M. d., Koks, B. J. (2013): A Palaearctic migratory raptor species tracks shifting prey availability within its wintering range in the Sahel. - Journal of Animal Ecology 82: 107-120.

[37] Vickery, J. A., Ewing, S. R., Smith, K. W., Pain, D. J., Bairlein, F., Skorpilov, J., Gregory, R. D. (2014): The decline of Afro-Palaearctic migrants and an assessment of potential causes. - Ibis 156: 1-22.

[38] Yohannes, E., Hobson, K. A., Pearson, D. J., Wassenaar, L. I. (2005): Stable isotope analyses of feathers help identify autumn stopover sites of three long-distance migrants in northeastern Africa. - Journal of Avian Biology 36: 236-341.

\section{ELECTRONIC APPENDIX}

This article has electronic appendices with basic data. 